\title{
TRACING THE STEPS OF NORWAY'S CARBON FOOTPRINT: LESSONS LEARNED FROM NORWAY AND THE EUROPEAN UNION CONCERNING THE REGULATION OF CARBON EMISSIONS
}

\author{
Kathryn M. Merritt-Thrasher
}

INTRODUCTION

Mainstream media debates regarding global warming run hot and cold over the question of man's direct contribution to the global warming dilemma through the massive use of fossil fuels, which create harmful carbon emissions. ' Substantive debates, however, acknowledge the effect of carbon emissions and seek to determine the relative merits of reducing emissions through quantity-based regulations versus tax-based approaches. ${ }^{2}$ The question of quota versus tax is made especially difficult given the fact that either strategy must be devised and implemented within the political structures of each country. ${ }^{3}$ If the question of tax versus quota was posed in a social and political vacuum, where only cost efficiency and total effectiveness of the policies were considered, the best answer would be much easier to ascertain definitively. Unfortunately, such a vacuum does not exist, and either strategy must be implemented via political processes that take into account the short and long-term effects on the citizens of each country rather than pure economic theory.

It is certain that inadequacies exist for both tax-based and quota-based strategies when attempting to reduce carbon emissions. ${ }^{4}$ In a tax-based approach, the burden of the tax falls more heavily on the poorest segment of the population, making it a regressive tax, which is exceedingly unpopular and difficult to impose. ${ }^{5}$ In a quota-based system, real progress toward the

* Kathryn Merritt-Thrasher is a J.D. Candidate at Indiana University School of Law Indianapolis, May 2012, and a Master of Business Administration Candidate, Indiana University Keiley School of Business - Indianapolis, May 2012. I would like to thank Professor Daniel Cole for his expertise and guidance. Additionally, my thanks to my husband, Daniel Thrasher, for his patience and support throughout the writing process and to my parents, Mark and Julie Merritt, for their constant inspiration and encouragement.

1. See Greenhouse Gases, Climate Change, and Energy, EnERgy Info. ADMIN., http://www.eia.doe.gov/oiaf/1605/ggccebro/chapterl.html (last modified Apr. 2, 2004).

2. See Eileen Claussen \& Judith Greenwald, Op-Ed., Handling Climate Change, in Pew Center on Global Climate Change (July 12, 2007), http://www.pewclimate.org/ press_room/opinion_editorials/oped_miamih07122007; discussion infra Part II.

3. See Claussen \& Greenwald, supra note 2; discussion infra Part V.C.

4. See Claussen \& Greenwald, supra note 2; discussion infra Part II.C.

5. See ERIC Williams et al., Nicholas Institute for ENVIRONMENTAL Policy Solutions and The Center on Global Change, A Convenient Guide to Climate Change Policy AND TECHNOLOGY 24 (vol. 2 2007), available at 
goal of lowered emissions is questionable given the fact that unrealistically low numbers are likely used as a starting point in order to "cushion" future emission costs. ${ }^{6}$ With all of the uncertainties surrounding the correct path to combating global warming, the best approach is to become educated on the true causes and effects of carbon emissions along with the success and failure of the strategies that have already been implemented in the worldspecifically by Norway and by the European Union.

Global warming, or, more generally, climate change, would likely occur even without the intervention of humans because harmful gases are released into the atmosphere naturally. ${ }^{7}$ However, humans contribute greatly to the release of gases such as carbon dioxide, methane, and nitrous oxide primarily due to the extraction and use of fossil fuels as energy sources. ${ }^{8}$ Carbon dioxide releases into the atmosphere due to burning coal, oil, natural gas, and gasoline for energy production. ${ }^{9}$ Methane gas releases into the atmosphere from natural sources such as rice paddies, but also from unnatural sources such as the burning of fossil fuels. ${ }^{10}$ Nitrous oxide releases into the atmosphere naturally from the world's rainforests and oceans and unnaturally from the manufacture of certain materials such as nylon and the use of agricultural fertilizers. ${ }^{11}$ Fluorinated gases, including hydrofluorocarbons, perfluorocarbons, and sulfur hexafluoride are synthetic greenhouse gases that are created in several industrial processes. ${ }^{12}$ Although fluorinated gases are usually released into the atmosphere in smaller quantities than the other gases, the potency level of these gases makes them especially dangerous to the environment. ${ }^{13}$ Collectively, these components are known as "greenhouse" gases, so named due to the effect upon the world's environment. ${ }^{14}$ They are also frequently referred to as "carbon emissions." It is believed that the collection and entrapment of these gases in the atmosphere is a major cause of global warming. ${ }^{16}$

http://www.nicholas.duke.edu/ccpp/convenientguide/PDFs/Climate\%20book\%20vol\% 202.pdf; discussion infra Part III.F.

6. Daniel H. Cole, Selling Hot Air: Emissions Trading and Offsets in Climate Policy, Chapter 3: European Union-Emissions Trading SCHEme, (Cambridge University Press) (forthcoming 2011) (manuscript at 21) (on file with author).

7. See Greenhouse Gas Emissions, U.S. ENVTL. PROT. AGENCY, http://www.epa.gov/ climatechange/emissions/index.html (last updated Apr. 14, 2011).

8. See id.

9. See id.

10. Id.

11. Id.

12. $I d$.

13. Id.

14. Id.

15. Id.

16. Id. 
The true cost of industrialization is measured by the negative impact on the Earth's atmosphere. ${ }^{17}$ While energy is vital to the existence of every country in the world, the current dependence on fossil fuels is creating a serious debate regarding the potential of an atmospheric nightmare due to the greenhouse gas emissions from burning fossil fuels. ${ }^{18}$ While an impending ecological catastrophe is unlikely, seriously negative effects are being brought upon the environment with the ever increasing levels of greenhouse gas emissions. ${ }^{19}$ It is imperative that technology turns in the direction of capturing, reducing, and eliminating these emissions in order to preserve and protect the Earth. ${ }^{20}$ While technology is advancing in the direction of protecting the Earth, world politics and policy will play the greatest role in either advancing or delaying measurable progress in reducing greenhouse gas emissions. ${ }^{21}$

To understand the basic science of greenhouse gases, it is necessary to identify the main sources of carbon emissions along with possible alternatives to the fossil fuels which cause a majority of the emissions. ${ }^{22}$ The world is currently so dependent upon fossil fuels to produce energy that it will be a cumbersome and expensive process to move from fossil fuels to clean energy sources. ${ }^{23}$ While the environmental effects of carbon emissions are very real, there are also economic realities related to creating safe, sustainable clean energy alternatives. ${ }^{24}$ Nations that take on the task of creating and utilizing clean energy sources may face a competitive disadvantage in the world marketplace as the extra cost of sustainable clean energy use is factored into the cost of production. ${ }^{25}$

Interestingly, one small country in the world that has spent nearly two decades aggressively attacking the problem of greenhouse gas emissions is Norway. ${ }^{26}$ Much information can be learned from the strategies Norway has implemented in an effort to curb carbon emissions, both independently and in cooperation with the European Union's carbon emission reduction strategies. ${ }^{27} \mathrm{~A}$ fundamental basis of Norway's plan is to create "an economy for the Earth-an economy for the common good." ${ }^{28}$ In other

17. See discussion infra Parts I.A-C.

18. See discussion infra Part I.A.

19. See discussion infra Part I.A.

20. See discussion infra Part I.C.

21. See discussion infra Part I.C.

22. See Greenhouse Gas Emissions, supra note 7; infra Parts I.B-C.

23. See discussion infra Part I.D.

24. See discussion infra Parts II, III.

25. See discussion infra Parts II, III.

26. See discussion infra Part II.

27. See discussion infra Part II.

28. Hans Chr. Bugge, Keynote Address at the Commemoration Seminar for the 10th Anniversary of the Centre for Development and the Environment at the University of Oslo: Sustainable Development-the Challenge for Norway (Mar. 29, 2001), in Preface to 
words, Norway is not simply seeking to create a plan for environmental protection; it is seeking to create a thriving economy with the responsible use of its natural resources for both the country's and the environment's good. Norway began by implementing one of the highest carbon tax rates in the world. These taxes were initially imposed on the amount of emissions created by any given industry in an effort to induce industries to reduce carbon emissions and invest in clean alternatives through a monetary incentive. $^{29}$ The results of this strategy are mixed, as one major problem stems from the exemption of several key industries possibly responsible for creating the greatest amount of emissions. ${ }^{30}$ It is important to consider how much of an improvement could be made in carbon reduction if no exemptions were allowed from the carbon tax. ${ }^{31}$

Although there are mixed reviews on the effectiveness of the carbon tax, there has been environmental progress. ${ }^{32}$ Additionally, much of the revenue collected by the carbon tax has been funneled into the support of research and development of "Carbon Capture and Storage" (sometimes called Carbon Capture and Sequestration), or CCS. ${ }^{33}$ Norway realized that the continued use of fossil fuels would be necessary and invested in a plan to capture and store the harmful emissions created by burning fossil fuels. ${ }^{34}$ Technology now exists to capture a large portion of these emissions and store them within the ocean floor, with the likelihood that only twenty percent of the carbon will return to the atmosphere in a time span of 300 years. ${ }^{35}$ The possibility of successfully capturing and storing carbon emissions provides a tremendous benefit because a majority of the world bases its infrastructure on the use of fossil fuels. ${ }^{36}$ The investment of time and money that is necessary to switch to clean energy sources is vast; therefore, the chance to continue to use fossil fuels while reducing harmful emissions provides an opportunity to make that transition in a slow, manageable progression. ${ }^{37}$

William Lafferty et al., REalizing Rio in Norway: Evaluative Studies of SUSTAINABLE DEVELOPMENT, at xix (2002), available at http://www.prosus.uio.no/ publikasjoner/Boeker/ relizing_rio_kapitelvis/04_preface.pdf.

29. Annegrete Bruvoll \& Bodil Merethe Larsen, Statistics Nor., Research Dep't, Greenhouse Gas Emissions in Norway-Do Carbon Taxes Work? 16 (2002), available at http://www.ssb.no/publikasjoner/DP/pdf/dp337.pdf.

30. Id. at 22 .

31. See discussion infra Parts II.A., II.C-D.

32. See discussion infra Part II.D.

33. Sonal Patel, Norway Leads the Way on CCS, POWER (Apr. 01, 2009), $\mathrm{http}: / / \mathrm{www}$.powermag.com/coal/Norway-Leads-the-Way-on-CCS_1820.html.

34. Id.

35. E. A. Parson \& D. W. Keith, Fossil Fuels Without CO2 Emissions, 282 SCI. 1053, 1055 (1998), available at http://www.pulp.tc/Parson_Field_Fossil_Fuels_without_ CO2.Science.pdf.

36. See discussion infra Part II.B.

37. See discussion infra Part II.B. 
Although it is a sovereign nation, Norway has strong geographic and economic ties to the rest of Europe. ${ }^{38}$ The European Union has introduced its own strategy to reduce carbon emissions, and although Norway is not a Member State, there is a cooperative effort between the two bodies. ${ }^{39}$ The European Union has put in place an Emissions Trading Scheme, comparable to the proposed Cap and Trade policies in the United States. ${ }^{40}$ A thorough analysis will evaluate the positive and negative effects of Norway's strategy not only in isolation but also in relation to and in cooperation with the strategies of the European Union. ${ }^{41}$ This Note will determine the advantages and disadvantages of Norway's strategy to reduce carbon emissions, ${ }^{42}$ both on its own and in conjunction with European Union strategies, ${ }^{43}$ in order for countries around the world to integrate the most beneficial tactics in a cohesive, worldwide attack against global warming. ${ }^{44}$

Part I of this Note will examine and explain carbon emissions, also known as greenhouse gas emissions or greenhouse gases. ${ }^{45}$ This section will detail the effects of the emissions on the environment as well as the human toll created by the release of greenhouse gases into the atmosphere and oceans. ${ }^{46}$ The various types and sources of harmful emissions will be identified, including both man-made sources and naturally occurring sources. ${ }^{47}$ Given the fact that fossil fuels create a large percentage of the harmful emissions, a variety of alternative energy sources are presented, ranging from solar and wind power to the ultimate alternative energynuclear power. ${ }^{48}$ Finally, Part I of this Note will examine the global dependence on fossil fuels as a primary source of the vital energy necessary to survive, along with the unique energy mix utilized by Norway.

Part II of this Note will focus on Norway, which has taken an aggressive stance on attacking the problem of greenhouse gas emissions. ${ }^{50}$ The discussion will examine the various strategies implemented by

38. The World Factbook - Norway, CIA, https://www.cia.gov/library/publications/theworld-factbook/geos/no.html (last updated Apr. 6, 2011).

39. See discussion infra Part III.

40. See Sergey Paltsev et al., MIT Joint Program on the Science and Policy of Global Change, Assessment of U.S. Cap-and-Trade Proposals 2 (2007), available at $\mathrm{http} / /$ apolloalliance.org/wp-content/uploads/2009/03/mitreport-cap-and-invest.pdf.

41. See discussion infra Parts II-III.

42. See discussion infra Part II.

43. See discussion infra Part III.

44. See discussion infra Part V.

45. See discussion infra Part 1.

46. See discussion infra Part I.

47. See discussion infra Part I.

48. See discussion infra Part I.

49. See discussion infra Part I.

50. See discussion infra Part II. 
Norway, with primary emphasis on the introduction of carbon taxes for many industries. ${ }^{51}$ Additionally, Part II details the introduction of CCS, which Norway has successfully implemented in an effort to capture many harmful emissions created during the extraction and use of fossil fuels. ${ }^{52}$ Part II concludes with an examination of the economic effects of the carbon tax on consumers and industries along with the measurable results of Norway's efforts. ${ }^{53}$

Part III of this Note will outline the carbon policies put forth by the European Union. ${ }^{54}$ Part III begins with a basic overview of the Kyoto Protocol along with detailed information regarding the groundbreaking European Union Emissions Trading Scheme (EU ETS). ${ }^{55}$ A discussion of the progression of the EU ETS policies from Phase I through the current version will be presented. ${ }^{56}$ Additionally, the actual environmental progress made due to those policies will be examined. ${ }^{57}$ Finally, this part will look at the compatibility of the EU ETS with non-Member States of the EU and with Norway in particular. ${ }^{58}$

Part IV of this Note examines the direction toward which Norway's carbon footprint is leading. ${ }^{59}$ The current status of the serious debate over the existing carbon tax rate and exemption scheme will be discussed. ${ }^{60}$ This section will look at changes that Norway has made and continues to make due to the influence of and cooperation with the EU policies. ${ }^{61}$ The successes and failures of Norway's two-decade long attempt to mitigate harmful carbon emissions will be evaluated. ${ }^{62}$ Finally, this Note will look at Norway's next steps as it continues its own plan of attack on climate change in cooperation with the European Union and the world as a whole. ${ }^{63}$

Part V of this Note provides an overview of what other nations in the world need to learn from the efforts put forth by Norway over the past two decades. ${ }^{64}$ Specifically, this Note highlights the importance of integrating CCS technology for countries to continue the extraction and use of fossil fuels while simultaneously reducing carbon emissions. ${ }^{65}$ Additionally, as

51. See discussion infra Part II.A.

52. See discussion infra Part II.B.

53. See discussion infra Parts II.C-D.

54. See discussion infra Part III.

55. See discussion infra Parts III.A-B.

56. See discussion infra Parts III.C-D.

57. See discussion infra Parts III.C-D.

58. See discussion infra Parts III.E-F.

59. See discussion infra Part IV.

60. See discussion infra Part IV.A.

61. See discussion infra Part IV.B.

62. See discussion infra Part IV.C.

63. See discussion infra Part IV.D.

64. See discussion infra Part V.

65. See discussion infra Part V.A. 
other countries consider legislative policies to induce emissions abatement, the structure and results of Norway's carbon taxation scheme should be carefully analyzed, especially with regard to the detrimental effect of subsidies and exemptions from the tax. ${ }^{66}$ Finally, when considering the current position of the United States, it is recommended that legislative progress start at the state or regional level and work upward, as it has proven nearly impossible to enact meaningful legislation at the national level. ${ }^{67}$ Overall, "global warming" is so named because it is a problem that must be addressed globally if real progress is to be made. ${ }^{68}$ The nations of the world would be well served to study and consider carefully the information provided by Norway's efforts, as well as the efforts put forth by the European Union. ${ }^{69}$

\section{WHAT IS ALL THE FUSS ABOUT CARBON EMISSIONS?}

Carbon emissions are widely known to cause pollution and play a major role in climate change. ${ }^{70}$ Additionally, Mark Jacobson, a professor of civil and environmental engineering at Stanford University, has directly linked one specific carbon emission, carbon dioxide, to increased human mortality. ${ }^{71}$ According to Jacobson's computer model, "[F]or each increase of 1 degree Celsius caused by carbon dioxide, the resulting air pollution would lead annually to about a thousand additional deaths and many more cases of respiratory illness and asthma in the United States." ${ }^{, 72}$ A direct cause and effect relationship is asserted between mortality and carbon dioxide, and as Jacobson states, "The study is the first specifically to isolate carbon dioxide's effect from that of other global-warming agents and to find quantitatively that chemical and meteorological changes due to carbon dioxide itself increase mortality due to increased ozone, particles and carcinogens in the air." 73 The link between carbon emissions and mortality extends beyond the effect on humans; the effect extends to every living species on the planet, and indeed, the planet itself. ${ }^{74}$

\section{A. The Effect of Greenhouse Gases on the Environment}

In addition to releasing carbon dioxide $\left(\mathrm{CO}_{2}\right)$, the burning of fossil

66. See discussion infra Part V.B.

67. See discussion infra Part V.C.

68. See discussion infra Part V.C.

69. See discussion infra Part V.C.

70. See Greenhouse Gas Emissions, supra note 7.

71. Louis Bergeron, Study Links Carbon Dioxide Emissions to Increase Deaths, STAN. REP., Jan. 3, 2008, http://news.stanford.edu/news/2008/january9/co-010908.html.

72. $I d$.

73. Id.

74. See discussion infra Part I.A. 
fuels for energy also releases nitrous oxide $\left(\mathrm{N}_{2} \mathrm{O}\right)$ and sulfur dioxide $\left(\mathrm{SO}_{2}\right)$ into the air. ${ }^{75}$ These chemicals rise very high into the atmosphere where they mix with water and oxygen to become acid rain. ${ }^{76}$ The acidic pollution becomes a part of not only rain but also snow, sleet, and fog. ${ }^{77}$ The longterm effect of acid rain causes damage to waterways, vegetation, crops, animals, and humans. ${ }^{78}$ These chemicals also become trapped in the ground-level ozone layer and create a haze known as smog. ${ }^{79}$ In addition to being unappealing and damaging to the environment, smog is deadly to humans, causing lung damage and respiratory diseases. ${ }^{80}$

While carbon dioxide released into the air causes health problems, carbon dioxide emissions are also making their way into the world's oceans, with nearly six million tons of carbon being absorbed into the oceans every day. ${ }^{81}$ The huge amounts of carbon are turning the ocean water acidic, creating a corrosive effect that will eventually affect food sources and habitats of many forms of ocean life, followed by many types of shellfish being affected, with the final human toll occurring when commercial fishing is no longer viable. ${ }^{82}$ More carbon is absorbed by the cold arctic waters, and research suggests that " $10 \%$ of the Arctic Ocean will be corrosively acidic by $2018 ; 50 \%$ by 2050 ; and $100 \%$ [of the] ocean by $2100 ., 83$ Furthermore, "“[o]ver the whole planet, there will be a threefold increase in the average acidity of the oceans, which is unprecedented during the past 20 million years." $" 84$

Finally, a fundamental cause of global warming or climate change ${ }^{85}$ is linked to the effects of greenhouse gas emissions. ${ }^{86}$ The trend for global warming, or increases in average temperature ranges, is evidenced by increases in extreme weather conditions, the disappearance of glacier mass, the melting of Arctic Sea and Antarctic Sea ice, and even the increased

75. What Causes Acid Rain?, U.S. ENVTL. Prot. AGENCY, http://www.epa.gov/acidrain/ education/site_students/whatcauses.html (last visited Apr. 14, 2011).

76. Id.

77. Id.

78. $I d$.

79. World of Earth Science, Smog, ENCYCLOPEDIA.COM (2003), http://www.encyclopedia.com/topic/smog.aspx.

80. Id.

81. See Robin McKie, Arctic Seas Turn to Acid, Putting Vital Food Chain at Risk, THE OBSERVER, Oct. 4, 2009, http://www.guardian.co.uk/world/2009/oct/04/arctic-seas-turn-toacid.

82. Id.

83. Id.

84. Id.

85. Throughout this Note, the terms "global warming" and "climate change" are used interchangeably.

86. See supra text accompanying notes $80-85$. 
spread of tropical diseases. ${ }^{87}$ The National Climatic Data Center reports that the current progression of average temperature increase per century is between 5.4 and 6.3 degrees Fahrenheit. ${ }^{88}$ This compares to a reported increase between five and nine degrees Fahrenheit in the past 18,000 years. $^{89}$ Given the current and potential destruction related to the effects of greenhouse gases on humans and the environment, the subject of carbon emissions, and the quest to reduce these emissions is an important, if not a vital, topic. ${ }^{90}$

\section{B. Sources of Carbon Emissions}

The largest source of carbon emissions across the globe occurs during the combustion of fossil fuels used to produce energy. ${ }^{91}$ Burning coal, oil, and gas in power plants, factories, and transportation devices releases the carbon stored in fossil fuels in the form of $\mathrm{CO}_{2}{ }^{92}$ In addition to the production of energy, $\mathrm{CO}_{2}$ is released during the production of certain minerals, such as cement and lime; metals, such as iron, aluminum, and lead; chemicals, such as ammonia; and through the use of certain petroleum based products. ${ }^{93}$ Since trees and plants naturally absorb carbon emissions from the air, mass deforestation can also lead to increased $\mathrm{CO}_{2}$ levels. ${ }^{94}$ Although $\mathrm{CO}_{2}$ is the primary gas emitted during unnatural and natural processes, additional gases such as methane and nitrous oxide are also released and are included in the "greenhouse" gases. ${ }^{95}$ Given the likelihood that global warming and environmental damage are directly linked to carbon emissions from burning fossil fuels, ${ }^{96}$ it is logical that the world would seek scientific methods to mitigate the emissions caused by extraction and combustion of fossil fuels while simultaneously exploring alternative sources to supply global energy needs.

\section{Alternatives to Carbon and Fossil Fuels}

As a substitute to fossil fuels, energy can be produced from a variety

87. Evidence of Global Warming, ECOBRIDGE, http://www.ecobridge.org/evidence_of_ global_warming.html (last visited Apr. 14, 2011).

88. Id.

89. Id.

90. See discussion supra Part I.A.; discussion infra Parts I.B, I.D.

91. Human-Related Sources and Sinks of Carbon Dioxide, U.S. ENVTL. PROT. AGENCY, http://www.epa.gov/climatechange/emissions/co2_human.html (last updated Apr. 14, 2011).

92. Id.

93. Id.

94. Id.

95. Id.

96. See discussion supra Part I.A. 
of alternative sources. ${ }^{97}$ These power sources include solar, wind, water (hydroelectric), hydrogen, and biofuels. ${ }^{98}$ While sun, wind, and water are readily available around the world and pose no threat of pollution, these sources are often downplayed as being unreliable. ${ }^{99}$ Skeptics question what will happen when the sun does not shine and the wind does not blow. ${ }^{100}$ While the technology to produce solar and wind power is readily available and relatively inexpensive, neither of these clean energy alternatives can provide adequate energy to replace fossil fuels. ${ }^{101}$ Waterpower, or hydroelectricity, has the capability to produce fairly vast quantities of electricity, but the proper sources are only available in certain areas, and degradation to land occurs both upstream and downstream of a dam. ${ }^{102}$ Biofuels such as ethanol or biodiesel have gained a great deal of support, and many countries have pursued biofuels as a cleaner, renewable alternative to gasoline. ${ }^{103}$ While it is true that biofuels are created from renewable sources such as corn, soy, barley, sugar cane, or animal fats, and that they produce significantly lower emissions when burned than fossil fuels, a significant amount of energy (electricity) is required to produce the fuels. ${ }^{104}$ The question that remains is whether biofuels create an overall advantage in the reduction of total emissions, or whether they simply create a reduction in the emissions from the transportation sector. ${ }^{105}$

Finally, the substitution of nuclear power for fossil fuels is extremely attractive from the perspective of reducing carbon emissions but is a volatile issue for the public due to both immediate and long-term safety issues. ${ }^{106}$ Nuclear power is created when energy is released by splitting heavy nuclei (fission) or by fusing light nuclei (fusion) in a nuclear reactor. ${ }^{107}$ Although the process of fission releases a great deal of useable energy and is $\mathrm{CO}_{2}$-negative, safe, long-term storage of the radioactive byproduct of nuclear waste is a matter of significant concern. ${ }^{108}$ Nuclear

97. See generally Renewable Biofuels and Other Alternative Fuel Sources, BEYOND FossiL FUEL, http://www.beyondfossilfuel.com/alternative_fuels.html (last visited Apr. 14, 2011) (highlighting the various sources of alternative fuels).

98. Id.

99. Id.

100. Id.

101. See id.

102. Id.

103. Biofuels: Ethanol and Biodiesel Explained, U.S. ENERGY INFO. ADMIN., http://tonto.eia.doe.gov/energy_in_brief/biofuels_use.cfm (last visited Mar. 21, 2011).

104. Id.

105. Id.

106. See M.S. Dresselhaus \& I.L. Thomas, Alternative Energy Technologies, 414 NATURE 332 (2001), available at http://docencia.izt.uam.mx/hcg/231236/material_ adicional/AlternativeEnergy.pdf.

107. Id.

108. Id. 
fusion could theoretically provide limitless, carbon-negative power; however, a safe, manageable engineering process has not been established. ${ }^{109}$ Therefore, due to safety concerns, nuclear power's value as an alternative fuel source will likely continue to decline. ${ }^{110}$

\section{Dependency on Carbon and Fossil Fuels}

The difficulty inherent in producing continuously reliable, affordable energy from any of the aforementioned alternative fuel sources brings the world back to dependence on fossil fuels. ${ }^{111}$ The entire world is dependent upon fossil fuels for one reason-reliable energy. ${ }^{112}$ In the United States, as of 2006, eighty-five percent of all energy was produced from burning fossil fuels, accounting for approximately sixty-six percent of total electricity and nearly all energy used for transportation. ${ }^{113}$ Forty-seven percent of this energy was created by burning petroleum, followed by twentyseven percent from the burning of coal and twenty-six percent from the burning of natural gas. ${ }^{114}$ In addition to the environmental and health problems caused by the burning of fossil fuels, a secondary problem for the United States is that in 2004, nearly sixty percent of the country's petroleum products were imported from non-domestic sources. ${ }^{115}$ The United States' reliance on other countries for its supply of energy is an issue that needs to be addressed and radically altered. ${ }^{116}$ While other nations have varying energy mix structures, fossil fuels are a predominant source of energy worldwide. ${ }^{117}$ Strategies for reducing the emissions from fossil fuels and eliminating the reliance on fossil fuels are a global concern. ${ }^{18}$

\section{E. A Case Study of Norway}

Norway is unique in the fact that fossil fuels are an important part of the country's economy, yet fossil fuels are a relatively unimportant domestic energy source. ${ }^{119}$ Norway is in the enviable position of having vast amounts of clean energy in the form of electricity produced from readily available hydro-power, providing many industries and residents the

109. Id.

110. Id.

111. See discussion supra Part I.C.

112. Fossil Fuel and Energy Use, SUSTAINABLE TABLE, http://www.sustainabletable.org/ issues/energy/ (last visited Apr. 14, 2011).

113. Id.

114. Human-Related Sources and Sinks of Carbon Dioxide, supra note 91.

115. See Evidence of Global Warming, supra note 87.

116. Id.

117. See Fossil Fuel and Energy Use, supra note 112.

118. See discussion infra Parts II, III.

119. See BRUVOLL \& LARSEN, supra note 29 , at $5,11$. 
ability to utilize emission-free electricity as a primary energy source. ${ }^{120}$ However, Norway does produce and export vast amounts of oil and natural gas; in fact, this sector of the economy was responsible for approximately twenty-five to thirty percent of Norway's total carbon emissions between 1990 and 1999..$^{21}$ Over the same period, even though Norway implemented an aggressive carbon taxation plan, $\mathrm{CO}_{2}$ emissions increased by nearly nineteen percent. ${ }^{122}$ Given the increase in carbon emissions even in the face of aggressive taxation, Norway has also placed a great deal of importance on the future of Carbon Capture and Storage as a means of reducing emissions at the source of extraction and production of fossil fuels. $^{123}$

\section{NORWAY'S CARBON MANAGEMENT STRATEGY}

In 1991 Norway introduced carbon taxes as the primary instrument of a multi-pronged national strategy to reduce greenhouse gas emissions. ${ }^{124}$ The tax rates imposed on carbon are among the highest in the world and are intended to create significant changes in the total carbon emissions in the nation. ${ }^{125}$ In addition to the introduction of carbon taxes, the Norwegian Pollution Control Authority implemented regulations aimed at treating landfills to reduce the methane emissions released during the decomposition process. ${ }^{126}$ These regulations were introduced in conjunction with carbon taxes as another component of the national climate policy. ${ }^{127}$ Finally, an additional facet of Norway's carbon management strategy is planned forest expansion in order to help mitigate the effect of carbon emissions on the atmosphere by absorbing carbon dioxide. ${ }^{128}$

Norway has aggressively pursued the fight against climate change not only through governmental policies but also by supporting technological

120. Id. at 8 .

121. Id. at 5,9 .

122. Id. at $4,22$.

123. Arne Walther, Ambassador, Royal Norwegian Embassy Japan, Presentation of Norwegian Perspectives at Norway-Japan Seminar on the Carbon Value Chain Organized by the Embassy, Mitigating Climate Change (Oct. 9, 2009), in Mitigating Climate Change, ROYAL NORWEGIAN EMBASSY IN TOKYO, JAPAN (July 1, 2010), http://www.norway.or.jp/ Embassy/english/ambassador/Ambassadors-Speeches/MitigatingClimateChange/.

124. BRUVOLL \& LARSEN, supra note 29 , at 4.

125. Id. at 21 .

126. Id. at 23.

127. Id. at 4.

128. See Rolfe Winkler, Norway Leads, US Lags on Environmental Policy, REUTERS (Oct. 10, 2007, 7:58 PM), http://www.reuters.com/article/bondsNews/idUSN102814562007 1010 ? $\mathrm{sp}=$ true. 
advancements through profits made in petroleum production. ${ }^{129}$ The country's economic system is a mixture of public and private control, meaning that the government has partial ownership in the energy companies. ${ }^{130}$ The blending of control allowed Norway to set up a fund derived from oil profits to move the country toward a green economy. ${ }^{131}$ This fund, the Norwegian National Oil Fund, has grown to the point of being the third largest sovereign fund in the world, behind the sovereign funds of Abu Dhabi and Saudi Arabia, which are also state-owned investment funds. ${ }^{132}$ Referred to simply as the "oil fund," "it invests the country's oil and gas income in stocks and bonds to save for future generations, when the hydrocarbons run out. Investments are made abroad to avoid overheating the economy." 133 Norway's fight against carbon emissions is intended to ensure the long-term future of the country. ${ }^{134}$ Norway's concerted effort to make a difference in global warming has been implemented in a thoughtful manner that is also producing future rewards and protections for the country. ${ }^{135}$

\section{A. Carbon Taxation-Pros and Cons}

The carbon taxes imposed on gasoline in Norway are particularly high, contributing to thirteen percent of the cost of fuel in 1999, followed by taxes on auto diesel at fourteen percent of the 1999 cost and light fuel oil at seven percent of the 1999 cost. ${ }^{136}$ Emissions levels caused by automotive transportation have decreased over the past decade, and although Norway does not have a domestic automotive industry, the majority of cars imported include technology to increase fuel efficiency, perhaps as a result of the high gasoline tax. ${ }^{137}$ Even with the high fuel taxes, citizens continue to drive record miles in record numbers and seem simply to accept the high cost of fuel as part of the price of the freedom to drive. ${ }^{138}$

One point of contention in Norway's carbon taxation plan is the fact that several key industries are either cushioned or exempted from the taxes,

129. Lois Quam, For Opportunities in the New Green Economy, We Should Look to Norway, NORWAY.COM (Oct. 2, 2009), http://blog.norway.com/2009/10/02/for-opportunitiesin-the-new-green-economy-we-should-look-to-norway/.

130. Id.

131. Id.

132. The Norwegian Oil Fund Still Growing, Norway.com (Sept. 22, 2009), http://blog.norway.com/2009/09/22/the-norwegian-oil-fund-still-growing/.

133. Id.

134. Id.

135. See discussion supra Parts I.A-D.

136. BRUVOLL \& LARSEN, supra note 29 , at 5.

137. Id. at 11.

138. Id. at $22-23$. 
while others bear the full burden of taxation. ${ }^{139}$ Norway is unique in that a large proportion of the energy consumed in the country is electricity, which is created by hydropower and produces no emissions. ${ }^{140}$ However, Norway does produce a great deal of petroleum, both for domestic use and for export. ${ }^{141}$ The emissions created by petroleum production contributed to approximately twenty-five to thirty percent of the total carbon emissions for Norway in the 1990s. ${ }^{142}$ While the government set relatively high tax rates on this industry, it either partially or totally exempted other industries that also create significant emissions, such as the metal processing industry. ${ }^{143}$ Additionally, "there [are] also exemptions for fishing, air and ocean transport, manufacturing of cement ... and land-based use of gas."144 For example, pulp and paper as well as herring flour manufacturers are subject to half carbon taxes. ${ }^{145}$ While these exemptions from the tax scheme may be necessary either politically or competitively, the fact remains that a great deal of additional progress could be made toward the goal of decreasing greenhouse gas emissions if the exemptions were not present. ${ }^{146}$

\section{B. Norway's Leading Edge Technology: Carbon Capture and Sequestration (CCS)}

Given the looming tax burden, Statoil, a Norwegian oil company, invested in innovative technology called CCS at its new Sleipner oil and natural gas field. ${ }^{147}$ The goal was to create a method of capturing the emissions created from the extraction of fossil fuels in order to avoid being taxed on emissions that enter the atmosphere. ${ }^{148}$ Norway's Sleipner Project for carbon capture and sequestration began in 1996 and is the first commercial application of emissions avoidance technology. ${ }^{149}$ Sleipner is an oil and gas field in the North Sea, and the carbon emissions created by operating the field were included in the carbon tax imposed by Norway. ${ }^{150}$ Since 1996 nearly one million metric tons of carbon emissions have been sequestered annually, and the company's investment was paid back in only

\footnotetext{
139. Id. at 5 .

140. Id. at 8.

141. Id. at 5.

142. $I d$.

143. $I d$.

144. Id.

145. $I d$.

146. Id. at 22 .

147. See Howard J. Herzog, What Future for Carbon Capture and Sequestration?, 35 ENVTL. SCI. \& TECH. 148, 151 (2001), available at http://sequestration.mit.edu/pdf/ EST_web_article.pdf.
}

148. See id.

149. See id.

150. Id. 
a year and a half in savings realized by avoiding the carbon tax. ${ }^{151}$ According to the Massachusetts Institute of Technology,

[c]arbon sequestration is a way to reduce greenhouse gas emissions. It complements two other major approaches for greenhouse gas reduction, namely improving energy efficiency and increasing use of non-carbon energy sources. Interest has been increasing in the carbon sequestration option because it is very compatible with the large energy production and delivery infrastructure now in place. ${ }^{152}$

Norway is considered the "Carbon Capture \& Storage (CCS) capital of the world." 153 The Sleipner Project has safely removed and stored more than ten million tons of $\mathrm{CO}_{2}$ from the Sleipner natural gas field without any evidence of leakage into the water. ${ }^{154}$ The economic and environmental success of CCS is evident, and this technology is being studied and implemented in other areas around the world. ${ }^{155}$

\section{Economic Effects of Carbon Taxation}

The potentially negative impact of a carbon tax on individual consumers has long been a stumbling block to imposing such a tax. ${ }^{156}$ The primary problem is that this type of tax is regressive; that is, the tax tends to affect the lowest income households unfairly, as this sector spends a greater percentage of income on energy. ${ }^{157}$ When comparing the economic effect of a carbon tax that creates an additional ten dollar cost per barrel of oil, it is projected that households in the lowest twenty percent income level would realize a $2.4 \%$ increase in energy spending as compared to their wealth, while households in the highest twenty percent income level would only see an increase of $0.8 \% .{ }^{158}$ The imposition of the heaviest burden of the tax onto the poorest segment of the population is problematic for passing such a tax. ${ }^{159}$ In an effort to address the problems caused by the regressive tax, Norway allocates a portion of the carbon tax revenue to

151. Id.

152. Carbon Capture and Sequestration Technologies@MIT, MASS. INST. OF TECH., http://sequestration.mit.edu (last visited Apr. 14, 2011).

153. David Hone, A Focus on CCS in Norway, SHELl (May 29, 2009), http://blogs.shell.com/climatechange/?p=469.

154. Id.

155. See supra notes $153-54$ and accompanying text; infra notes 156-58 and accompanying text; discussion infra Part III.

156. See Williams ET AL., supra note 5, at 24.

157. See id.

158. Id. at 13-14.

159. Id. 
offset individual income tax. ${ }^{160}$ With this strategy, "[i]n 1999, the tax revenue reduced personal income taxes by an average of 790 Norwegian krones $(\$ 117)$ per person. Other portions of the tax revenues have been spent on research and development of renewable energy and energy efficiency technologies."161

A further consideration when implementing a carbon tax is the possibility of creating a competitive disadvantage in the world marketplace for industries affected by the tax. ${ }^{162}$ The carbon tax increases a company's production costs, which then contributes to a higher market price or a company's lower profitability. ${ }^{163}$ A competitive disadvantage could occur in a given market if a country unilaterally enacts a carbon tax while all other international competitors do not. ${ }^{164}$ However, the intentions of the Kyoto Protocol are for all countries to create a method of reducing carbon emissions, both by enacting taxes and by means of technological advances. ${ }^{165}$ Given the proposal of worldwide cooperation within the Kyoto Protocol,

if carbon taxes were used as the sole means of meeting the Kyoto emissions obligations, the level of the taxes would be very high and could thus have significant implications for competitiveness. However, since all industrial countries will have to reduce emissions under the Kyoto Protocol, industries in different countries will almost simultaneously experience an increase in their costs. ${ }^{166}$

There is no doubt that a carbon tax adds cost to the bottom line of any industry and therefore eventually to the consumer. ${ }^{167}$ However, it is one method that can ensure greater efficiencies, new technology, and concerted efforts to minimize levels of harmful carbon emissions. ${ }^{168}$

\section{Measureable Effects of Norway's Carbon Policy}

Between 1990 and 1999, Norway experienced gross domestic product

160. WILLIAMS ET AL., supra note 5, at 20.

161. Id.

162. See ZhongXiang Zhang \& Andrea Baranzini, What Do We Know About CARBON TAXES? 17 (2003), available at http://mpra.ub.uni-muenchen.de/13225/1/envwp carbon tax03.pdf.

163. See id. at 18.

164. See id.

165. See id. at 3; infra Part III.A.

166. ZHANG \& BARANZINI, supra note 162 , at 20 .

167. See id. at 18.

168. See supra Part I.A. 
growth of thirty-five percent. ${ }^{169}$ With this substantial increase in gross domestic product, there is an expectation for emissions to increase due to increased energy demands. ${ }^{170}$ During this period, actual carbon emissions increased nineteen percent, even with an aggressive carbon taxation policy. ${ }^{171}$ While the increase in emissions is less than the percentage increase in gross domestic product, the main question is how much influence the carbon tax has on the quantity of emissions. ${ }^{172}$ One study indicates that the direct effect of the tax has been relatively small; without the tax, actual emissions during the period would have increased approximately $21.3 \%$, leaving an estimated reduction in emissions directly related to the carbon tax of only $2.3 \% .{ }^{173}$ The study instead contributes a switch in the energy mix to clean hydroelectricity as a major contributor to the reduction, along with the abatement of landfill gases, which reduced the emissions of methane, $\mathrm{N}_{2} \mathrm{O}$, and $\mathrm{SF}_{6}{ }^{174}$ Even though the direct effect of the tax may be small, perhaps the high carbon taxes provided incentive to substitute fossil fuels with clean energy sources, where available, in order to avoid the tax. ${ }^{175}$

Again, a primary reason cited for a less than anticipated direct reduction through the carbon tax is the broad exemption allowed to several fossil fuel intensive industries. ${ }^{176}$ These exemptions from the carbon tax were

principally motivated by concern about competitiveness. The industries, in which we expect the carbon tax to be most efficient in terms of downscaling of the production and reduced emissions, are the same industries which are exempted from the carbon tax. The zero-tax industries consist mainly of the process industry, which explains why there is a close to zero effect of the tax on process related $\mathrm{CO}_{2}$ emissions. If the metal sector and industrial chemicals had not been exempted from the carbon tax, a large share of these sectors would have proven unprofitable. Likewise, the low possibilities to substitute from heating oil for

169. BRUVOLL \& LARSEN, supra note 29, at 22.

170. Id. at 9.

171. Id. at 22 .

172. See id. at 22.

173. Id. at 22.

174. Id. at $16,23$.

175. See id. at 16.

176. Id. at 23. 
fishing and sea transport indicate that a tax would have reduced the production level in these industries. ${ }^{177}$

As previously stated, an exemption is likely in place due to political or economic realities; however, it does lead to a detrimental effect on the overall goal of measureable emission reduction. ${ }^{178}$

\section{THE EUROPEAN UNION CARBON POLICY}

\section{A. The Kyoto Protocol}

In December of 1997, the Kyoto Protocol to the United Nations Framework Convention on Climate Change was signed into agreement. ${ }^{179}$ The Kyoto proposal allows

countries considerable flexibility in the choice of domestic policies to meet their emissions commitments. Possible policies include carbon/energy taxes, domestic emissions trading, command-and-control regulations and other policies. Economists and international organizations have long advocated carbon taxes, because they can achieve the same emissions reduction target at lower costs than conventional command-and-control regulations. Moreover, carbon taxes can act as a continuous incentive to search for cleaner technologies, while for command-and-control regulations there is no incentive for the polluters to go beyond the standards. ${ }^{180}$

The Kyoto proposal outlined a system of tradable permits of $\mathrm{CO}_{2}$ emissions among Annex I countries ${ }^{181}$ with the intention of creating an efficient

177. Id. at 22.

178. See supra Parts II.C-D.

179. Kyoto Protocol to the United Nations Framework Convention on Climate Change, Dec. 10, 1997, U.N. Doc. FCCC/CP/1997/7/Add.1, 37 I.L.M. 22 (1998); Kyoto Protocol, United Nations Framework CONVEnTION on Climate Change, http:/unfccc.int/ kyoto_protocol/ items/2830.php (last visited Apr. 14, 2011).

180. ZHANG \& BARANZINI, supra note 162 , at 4.

181. Annex I parties include Australia, Austria, Belarus, Belgium, Bulgaria, Canada, Croatia, Czech Republic, Denmark, Estonia, European Union, Finland, France, Germany, Greece, Hungary, Iceland, Ireland, Italy, Japan, Latvia, Liechtenstein, Lithuania, Luxembourg, Monaco, Netherlands, New Zealand, Norway, Poland, Portugal, Romania, Russian Federation, Slovakia, Slovenia, Spain, Sweden, Switzerland, Turkey, Ukraine, United Kingdom of Great Britain and Northern Ireland, United States of America. List of Annex I Parties to the Convention, UnITEd Nations Framework Convention on Climate 
method to achieve measurable emissions reductions. ${ }^{182}$

\section{B. The European Union Emissions Trading Scheme}

To achieve the goals set forth in the Kyoto Protocol, the European Union established the European Union Emissions Trading Scheme (EU ETS), which applies to industries that create approximately fortyfive percent of the total carbon emissions in Europe. ${ }^{183}$ The industries covered by the EU ETS include "facilities for electricity generation, the production and processing of ferrous and non-ferrous metals, energy intensive activities in the mineral industry and the pulp, paper and board production." ${ }^{\prime 84}$ The EU ETS focuses on the point of combustion where carbon emissions are created. ${ }^{185}$ This provides incentive for industries creating the emissions to invest in improved efficiencies and technologies to minimize the costs incurred from emissions. ${ }^{186}$ As the current EU ETS covers a rather narrow segment of heavy industry, progress remains to be made in other areas. ${ }^{187}$ Specifically, the goal is to include additional domestic industries not currently included in the EU ETS, as well as industries abroad, that may eventually join in international emissions trading. ${ }^{188}$

\section{Past, Present, and Future Strategy of the EU ETS}

The EU ETS was initiated in 2005, signaling the EU's intention to become a leading player in the fight to curb carbon emissions. ${ }^{189}$ As the EU is one of the world's major contributors to greenhouse gas emissions, it is fair that the EU has become a leading player in the fight to curb carbon emissions. ${ }^{190}$ The adoption of an emissions trading scheme instead of a direct carbon tax provides a level of flexibility for industries. ${ }^{191}$ In essence,

CHANGE, http://unfccc.int/parties_and_observers/parties/annex_i/items/2774.php (last visited Apr. 14, 2011).

182. Kyoto Protocol, supra note 179.

183. Gernot Klepper \& Sonja Peterson, Emissions Trading, CMD, JI, and More: The Climate Strategy of the EU, 27 THE ENERGY J. 1, 1 (2006), available at http://www.hmtreasury.gov.uk/d/Klepper-Peterson-2006.pdf.

184. Id.

185. See PALTSEV ET AL., supra note 40 , at 4.

186. See id.

187. See id.

188. Id. at 6 .

189. EU Emissions Trading System (EU ETS), Dept. of Energy \& Climate Change (U.K.), http://www.decc.gov.uk/en/content/cms/what_we_do/change_energy/tackling_clima/ emissions/eu_ets/eu_ets.aspx (last visited Apr. 14, 2011).

190. Atle C. Christiansen \& Jorgen Wettestad, The EU as a Frontrunner on Greenhouse Gas Emissions Trading: How Did it Happen and Will the EU Succeed?, 3 Climate POL'Y 3 , 4-5 (2003).

191. Id. at 5 . 
certain industries that would face high costs to curb emissions could opt to purchase additional carbon allowances from other industries that have lower carbon abatement costs. ${ }^{192}$ Industries able to change their energy usage in a cost-effective manner to reduce emissions have the ability to offset the costs incurred by selling unused carbon allowances in the trading scheme. ${ }^{193}$

\section{Progress of the EU ETS From Inception to Present}

Currently, the emissions trading scheme in the European Union encompasses approximately forty percent of all EU greenhouse gas emissions. ${ }^{194}$ This surprisingly small percentage is due to the fact that the EU ETS focuses on $\mathrm{CO}_{2}$ rather than attempting to encompass the entire array of greenhouse gases. ${ }^{195}$ The EU directive is in sharp contrast to the Kyoto Protocol, which called for controlling all greenhouse gases and targeting emissions from all sources, rather than just carbon emissions. ${ }^{196}$ The rationale behind limiting the EU ETS to carbon emissions was based on the belief that

[i]nclusion of other greenhouse gases . . . is desirable but would be dependent on resolving monitoring, reporting and verification issues .... [T] he monitoring uncertainties are still too great for greenhouse gases other than carbon dioxide. For these reasons, emissions of greenhouse gases other than carbon dioxide are not included in the first phase of the scheme. ${ }^{197}$

Within each Member State of the EU, industries in the included sectors are required to obtain permits, with one permit equal to one ton of $\mathrm{CO}_{2}$ emissions, representing the allowable amount of carbon emissions. ${ }^{198}$

192. Id.

193. Id.

194. COLE, supra note 6 (manuscript at 14).

195. Raymond Kopp, Senior Fellow at Resources for the Future, Cong. Testimony Prepared for the U.S. Senate Comm. on Energy and Natural Res. Roundtable on the European Emissions Trading Scheme: An Overview of the European Union Emissions Trading Scheme 1 (Mar. 26, 2007), in An Overview of the European Union Emissions Trading Scheme, RESOURCES FOR THE FUTURE, http://www.rff.org/RFF/Documents/RFFCTst_07-Kopp.pdf (last visited Apr. 14, 2011).

196. CoLE, supra note 6 (manuscript at 15).

197. Id. (quoting Commission Proposal for a Directive of the European Parliament and of the Council Establishing a Scheme for Greenhouse Gas Emission allowance Trading within the Community and Amending Council Directive 96/61/EC, at 10, COM (2001) 581 final (Oct. 23, 2001)).

198. Id. (manuscript at 18). See also Council Directive 2003/87, art. 6(2)(e), 2003 O.J. (L 275) 32 (EC). 
Detailed requirements were put forth for reporting and verifying actual emissions, including independent verification of emission rates and substantial penalties for non-compliance. ${ }^{199}$ With the current emphasis on emissions trading, the EU had to focus on how to devise emissions allocations efficiently. ${ }^{200}$ In theory,

there are two basic methodologies for initial allocation of allowances. One option is some form of 'grandfathering', whereby allowances are distributed to companies on the basis of historical emissions or according to a certain performance standard ('benchmarking'). The alternative is that the government requires companies to buy allowances, for instance at a fixed price or in an auction. ${ }^{201}$

The EU opted to use a grandfathering method for allocation, in part to minimize objections of Member States against the alternative auction method. ${ }^{202}$ The EU sets forth a clear system of compliance and reporting along with considerable financial penalties in order to ensure across-theboard compliance with the system. ${ }^{203}$ Given that the EU ETS is directed at the point of combustion, it is expected that the companies covered by the system will directly bear the cost of emissions reduction both by the cost of allocation permits and by pursuing improved efficiency or alternative fuel sources. ${ }^{204}$ Interestingly, however, during a trial phase of the system

electricity price changes have appeared to reflect not so much the direct mitigation expenses but the changing marginal cost of permits, even though they were distributed for free. Given that the electricity markets are mostly deregulated in Europe such a pass through of permit price is, or should have been, expected. ${ }^{205}$

In the end, any actual or potential additional costs related to the reduction of carbon emissions will ultimately be borne by the consumer. ${ }^{206}$

At the beginning of Phase I of the EU ETS, approved carbon emissions allowances were in place equaling one and a half billion tons of

199. See ColE, supra note 6 (manuscript at 18). See also Council Directive 2003/87, arts. 6-14, 2003 O.J. (L 275) 32 (EC).

200. See Christiansen \& Wettestad, supra note 190, at 11.

201. Id.

202. Id.

203. Id.

204. PALTSEV ET AL., supra note 40 , at 4.

205. Id.

206. See id. 
$\mathrm{CO}_{2}$ per year, which was nearly 100 million tons greater than actual current emissions. ${ }^{207}$ This number can be explained by several possibilities, including Member States not wanting to impose undue hardship on the sectors involved, aggressive lobbying efforts by the industries, and the possibility of individual Member States creating excess allowances in order to benefit monetarily by trading them to other Member States. ${ }^{208}$ The trading of allowances between industries and Member States began with Phase I on January 1, 2005, and "approximately 291 million allowances were traded in the EU ETS in its first year of operation. By October of 2006, the number of traded allowances had grown to 787 million." ${ }^{, 209}$ While the volume of trading has steadily increased, the price of the allowances has fluctuated wildly, starting below $€ 10 /$ ton, then rising to $€ 30 /$ ton, and finally settling between $€ 10 /$ ton and $€ 20 /$ ton $^{210}$ An unfortunate byproduct of the trading scheme is the fact that many consumers were essentially charged for the potential cost of emissions in the form of higher rates for energy sources even though the allowances were provided to the industry for free and the industry had the ability to sell excess allowances for profit. ${ }^{211}$

As the first phase of the trading scheme ended in 2007, the word "failure" was often used to describe the outcome. ${ }^{212}$ The combination of the fact that no real progress was made toward actually reducing carbon emissions along with the fact that consumers were paying higher costs while several powerful industries raked in huge windfall profits from trading "free" emissions allowances left many citizens of the EU fully embracing the word "failure" to describe the EU ETS. ${ }^{213}$ From the point of view of the scheme's framers, however, it was considered a success because a viable framework was put in place within each Member State from which to begin working toward real and measureable progress in reducing carbon emissions during the next phase. ${ }^{214}$

The major difference in Phase II of the EU ETS was the fact that instead of basing emission allocations on pure estimates, the allocations were now based on actual, measured emissions volume collected during Phase I. ${ }^{215}$ Therefore, industries that attempted to reduce their cost of

207. Cole, supra note 6 (manuscript at 23-24). See also Michael Grubb, Christian Azar \& U. Martin Persson, Commentary, Allowance Allocation in the European Emissions Trading System, 5 Climate POL'Y 129, 129-30 (2005).

208. Cole, supra note 6 (manuscript at 24).

209. Id. at 29. One allowance accounts for the equivalent of one ton of $\mathrm{CO} 2$ emissions. See id. at 18. See also Council Directive 2003/87, art. 6(2)(e), 2003 O.J. (L 275) 32 (EC).

210. COLE, supra note 6 (manuscript at 29-30).

211. Id. (manuscript at 31-32).

212. Id.

213. Id. (manuscript at 32).

214. Id.

215. Id. (manuscript at 33). 
compliance by estimating a higher number of emissions in order to receive adequate or surplus allocations now would be issued allocations based on real numbers of the actual emissions created in the previous year. ${ }^{216}$ These companies would then need to strive to reduce emissions from the actual prior year number rather than the inflated estimate previously presented. ${ }^{217}$ Even though several Member States attempted to submit plans with inflated allocations, the plans were rejected and the Member States were forced to reduce the allocations drastically in order to pursue true progress toward $\mathrm{CO}_{2}$ reductions. ${ }^{218}$ With these more stringent requirements regarding the number of allowable allocations, an estimated $6.8 \%$ reduction over actual 2005 emissions was anticipated. ${ }^{219}$ Additional controls over emissions allowances were put in place with a 2009 Directive to the EU ETS, which stated that "starting in 2013, more than $50 \%$ of allowances will be auctioned, rising to $100 \%$ by $2027 ., 220$ Therefore, while the allowances were initially offered for free, by 2013 only fifty percent of the allowances will be free, fifty percent will have to be purchased, and by 2027 all emissions allowances will have to be purchased. ${ }^{221}$ This is what provides the incentive for industries to reduce emissions in order to reduce the expense of purchasing allowances. ${ }^{222}$ In addition, the directive carried a requirement that

50 percent of all auction revenues be used for (among other purposes) reducing GHG emissions, developing renewable energy resources (pursuant to a related EU policy mandating 20 percent of energy production from renewable sources by 2020), carbon capture and storage, measures to avoid deforestation or increase afforestation, and public transportation. ${ }^{223}$

Clearly, the EU recognizes the importance of a multi-pronged plan to make actual headway in achieving measurable emissions reductions in addition to the importance of more centralized control over the continued implementation of the EU ETS.

Perhaps the most important addition made to the EU ETS by the 2009 Directive is the recognition of CCS as a necessary component for successful

216. Id.
$217 . I d$.
218. Id.
219 . Id.
220. Id. (manuscript at 40 ).
221. Id.
222. Id. (manuscript at 41 ).
223. Id. (manuscript at 40 ). 
emissions reduction. ${ }^{224}$ Specifically,

on March 26, 2009, the European Parliament and Council approved a Directive that expressly recognizes carbon capture and storage (CCS) as a 'bridging technology that will contribute to mitigating climate change.' The Directive's Preamble (para. 5) predicts that carbon emissions avoided by CCS could amount to 15 percent of total required emissions reductions. ${ }^{225}$

The fact that the EU is now focused on including CCS technology as an important component of its emissions reduction strategy brings Norway directly into play, even though Norway is not a Member State. ${ }^{226}$ Norway's leadership in the cutting edge CCS technology could play a vital role in the new and improved EU ETS.

\section{E. Compatibility of EU ETS with Non-Member States}

Although the Emissions Trading Scheme being utilized by the EU is intended for compliance by Member States, the scheme is ultimately geared toward compatibility with other nations in order to synergize a cohesive, global attack on greenhouse gas emissions. ${ }^{227}$ This goal of a compatible trading scheme is only partly due to lofty, "green" goals. ${ }^{228}$ It is also due to the fact that many states are already in the process of, or nearing the process of, becoming Member States of the EU, and in several of these states the abatement costs of changing fuel sources are significantly lower than in many current Member States. ${ }^{229}$ Therefore, a trading scheme that would integrate with many nations and incoming Member States would prove beneficial, especially since new Member States are automatically required to adopt all EU legislation. ${ }^{230}$ Additionally, greater participation in the trading scheme by additional countries would infuse a larger volume of allocation trading, leading to greater efficiencies in the trading system. ${ }^{231}$ Finally, the ability to develop a successful trading scheme not only for Member States but also across many nations would establish the EU as the

224. Id.

225. Id. (manuscript at 41 ).

226. Id.

227. See Christiansen \& Wettestad, supra note 190, at 12.

228. See id.

229. See id.

230. See id.

231. See id. 
definitive leader in the fight to curb carbon emissions and global warming. ${ }^{232}$

\section{F. Norway's Participation as a Non-Member State}

A primary goal of the EU strategy is to create an overall cap on emissions levels of various industries in order to preserve the competitiveness of those industries across Europe. ${ }^{233}$ According to this strategy,

it is recognized that, at least initially, not all Member States may be able to join the system and that the sectors included may differ from one country to another. The expansion of the system to allow opt-ins from non-included sectors and closely allied non-EU members (Norway) is also anticipated. ${ }^{234}$

Although Norway is not a Member State of the EU, since 1994 it "has been part of the European Union's internal market through the Agreement on the European Economic Area (EEA Agreement)."235 "Most EU legislation in the environmental field is also EEA-relevant, which means that Norway to a large degree has the same obligation to implement EU environmental legislation as the Member States."236

In order to pursue greater levels of greenhouse gas reductions, Norway put together a "Quota Commission" made up of participants from government, industry, and academia. ${ }^{237}$ The purpose was to develop a useable cap-and-trade system to utilize in addition to the existing carbon taxation in an effort to further reduce carbon emissions. ${ }^{238}$ Norway's proposed trading scheme is significantly more expansive than the EU Emissions Trading Scheme in that it would include more than eightyeight percent of the country's greenhouse gas emissions, rather than

232. See id.

233. A. Denny Ellerman, Mit Joint Program on the Sci. \& Policy of Global Change, Trade Permits for Greenhouse Gas Emissions: A Primer With Particular REFERENCE TO EUROPE 13 (2000), available at http://web.mit.edu/globalchange/www/ MITJPSPGC_Rpt69.pdf.

234. $I d$.

235. Stine Aakre \& Asbjørn Torvanger, Ctr. for Int'l Climate \& Envtl. Research, Case Studies on Climate Change Response Policies and Strategies of SELECTED ANNEX I COUNTRIES: NORWAY AND SWEDEN 11 (2007), available at http://www.cicero.uio.no/media/ 5960.pdf.

236. Id.

237. ELLERMAN, supra note 233 , at 13-14.

238. Id. 
focusing solely on $\mathrm{CO}_{2}{ }^{239}$ As expected, the greatest area of contention within the Quota Commission surrounds the method of allocation. ${ }^{240}$ Regarding the options presented for allocation,

[a] bare majority of six (out of eleven) recommends that the government auction the permits and that the proceeds accrue to the government to reduce other taxes and to earn a "“double dividend." The sole industry representative and an environmental NGO recommended grandfathering of permits, and the other minority group consisting of civil servants from several ministries argued that allocation is a political issue and outside of the Commission's mandate. ${ }^{241}$

The vast discrepancies in opinion regarding the proper way to allocate emissions allowances is a crucial sticking point facing all countries currently contemplating a cap-and-trade system.

\section{WHAT DIRECTION IS NORWAY'S CARBON FOOTPRINT LEADING?}

\section{A. The Debate Over Taxes and Exemptions}

Nearly two decades after its inception, a major topic currently being debated in Norway is the existing emissions tax structure and its inclusion of allowances and exemptions for certain industries. ${ }^{242}$ A theory of "pure" economics would call for equal taxes for all emissions from all sources. ${ }^{243}$ The tax scheme imposed in Norway, however, is not a "pure" tax; rather, it is influenced by politics and world markets. ${ }^{244}$ For instance,

in Norway, tax rates for greenhouse gas emissions vary from zero to NOK 872 per tonne $\mathrm{CO}_{2}$ equivalent. Compared with the current carbon price in the EU emissions trading scheme, Norwegian households pay about NOK 0.5 billion more than they should for their $\mathrm{CO}_{2}$ emissions, and the oil and gas extraction sector pays about NOK 1.5 billion too much. In contrast, the other polluters

239. Id. at 14.

240. Id.

241. Id.

242. See Williams ET AL., supra note 5, at 20.

243. See Finn Roar aune \& Knut EINar Rosendahl, analysis of Selected RESOURCE AND ENVIRONMENTAL IsSUes, in SElected Resource and ENVIRONMENTAL IsSUES: NATURAL RESOURCES AND THE ENVIRONMENT 229, 232 (2008), available at http://www.ssb.no/ english/subjects/01/sa_nrm/nrm2008/kap15-resources.pdf.

244. Id. at 231 . 
in the process industry, together with the transport sector, gas terminals, oil refineries, and the fisheries sector, pay NOK 2.8 billion less than they should in a cost-efficient system. ${ }^{245}$

The industries that are creating carbon emissions, yet paying reduced taxes, are benefiting from a system of exemptions and lower tax rates intended to protect the worldwide competitiveness of certain sectors. ${ }^{246}$. This system of favoritism is a topic for serious debate within Norway.

Currently, the Research Council of Norway is studying the disparity between the current policy regarding carbon taxes and a tax scheme recommended by pure economic theory. ${ }^{247}$ The assumption is that the current system of varying levels of taxes and subsidies prevents true cost efficiency. ${ }^{248}$ The current carbon tax structure ranges from a nearly zero tax for sectors included in the tax exemption to a substantial tax of nearly NOK 300 per ton of $\mathrm{CO}_{2}$ for the average household, whose primary emissions include petrol, diesel, fuel oil, and kerosene, all of which are levied with a hefty carbon tax. ${ }^{249}$ Still, the highest tax rate is imposed on the actual extraction and production of oil and gas. ${ }^{250}$ Regarding Norway's differing tax rates for various sectors,

[t]he $\mathrm{CO}_{2}$ tax contains exemptions for coal and coke used in production of cement and lightweight expanded clay aggregate in the processing industry and has a reduced rate for the paper and pulp industry and the production of fishmeal. A tax on heating oil (mineral oil) is applicable for the paper and pulp industry and the production of fishmeal. The tax on consumption of electricity is applicable for all manufacturing industries and greenhouse industries. ${ }^{251}$

Although these exemptions and disparities in tax rates do not comply with pure economic theory, they were set in place presumably to protect the included sectors from being priced out of world competitiveness due to

245. Id. at 232 .

246. Id.

247. Id. at 250 .

248. Id.

249. Id.

250. Id.

251. Lynn Price et al., LaWrence Berkeley National Laboratory, TaX and FisCal POLICIES FOR PROMOTION OF INDUSTRIAL ENERGY EFFICIENCY: A SURVEY OF INTERNATIONAL EXPERIENCE 7 (2005), http://www.efchina.org/csepupfiles/workshop/2006102695218825. 1165929103267.pdf/IntlExp_FTpolicies_IndustrialEE_EN.pdf. 
taxes aimed at an overall reduction of carbon emissions. ${ }^{252}$ While economists looking to create the most cost efficient and effective measures to reduce carbon emissions would not allow such exemptions, real world implementation requires the tax structure to be enacted through politics and policy. ${ }^{253}$ It is difficult to enact legislation imposing emissions taxes on domestic industries that are so burdensome as to make the industry noncompetitive in the world market. ${ }^{254}$ Therefore, the inadequacies and disparities of the emissions tax scheme are likely to continue. ${ }^{255}$

\section{B. Incorporating European Union Policies}

Beginning in 2006, Norway expanded its policies to encompass the policies set forth in the EU ETS. ${ }^{256}$ With this change, the cost-effectiveness of greenhouse gas reductions improved for several market sectors. ${ }^{257}$ Even with the cost improvement, the combined sectors with little or no exemptions still pay nearly NOK 2.1 billion more in carbon taxes than they would in a totally pure economic system that did not include any subsidies. ${ }^{258}$ It would seem that the goal of Norway's carbon emissions strategy is not only to reduce carbon emissions, but also to generate tax revenue from sectors and industries that can "afford" it. ${ }^{259}$ Many economists still believe that all greenhouse gas emissions should be taxed equally, without any form of subsidy for any sector. ${ }^{260}$ These purists look to the possibility that future rules of competition within the European Economic Area (EEA), of which Norway is a party, will help to move Norway's climate strategy more toward a pure economic strategy and away from policies driven by politics. ${ }^{261}$

Norway not only provides critical energy resources for other nations, but it also provides energy in the most responsible manner possible for the environment. ${ }^{262}$ The oil and gas exported from Norway may possibly be the "cleanest" fuel sources in terms of carbon emissions due to the extraordinary efforts of Norway to utilize CCS and other strategies to minimize greenhouse gas emissions during the extraction and production of fuel. ${ }^{263}$ Additionally, Norway is committed not only to expanding its

252. AUNE \& ROSENDAHL, supra note 243, at 249.

253. Id.

254. Id.

255. Id.

256. Id. at 251 .

257. Id.

258. Id.

259. See id.

260. Id. at 251.

261. Id.

262. Walther, supra note 123

263. Id. 
utilization of CCS domestically in order to produce cleaner fuel, but also it intends to partner with other countries such as China to develop CCS technology for new coal plants in an effort to reduce global carbon emissions. ${ }^{264}$ Given the predicted increase in world population and the corresponding increase in energy demand, Norway envisions its CCS technology as playing a key role in helping mitigate the expected increase in greenhouse gas emissions. ${ }^{265}$ Furthermore, Norway is dedicating twenty percent of its EEA contributions for the next five years to fund CCS projects in various EU Member States, in addition to lending substantial technological support. ${ }^{266}$ Along with the UK, Norway is funding a study of the viability of using the North Sea as a potential site for CCS installations. ${ }^{267}$ The obvious benefit of CCS is the fact that the technology provides a responsible manner for the world to continue the widespread production and use of fossil fuels for energy while simultaneously reducing the harmful emissions that cause environmental damage. ${ }^{268}$ Norway's foray into, and perfection of, CCS technology is likely the greatest contribution that will be made by this small country to the reduction of global emissions.

\section{The Successes and Failures of Norway's Strategy}

Over the past fifteen years, there have been some additional, specific areas of progress in Norway's fight to curb domestic greenhouse gas emissions. ${ }^{269}$ During this time, recycling of household waste has increased from nearly zero percent to over forty percent, greatly helping moderate the harmful effects of landfill gases. ${ }^{270}$ This would be considered a victory in itself; however, the progress is mitigated by the fact that within that same time period, the amount of household waste created per person has increased over fifty percent, thereby totally eliminating the positive benefit of the recycling program. ${ }^{271}$ If one chooses to view this in a positive light, however, the beneficial results of the recycling program did mitigate the harmful effects of the fifty percent increase per person of household waste. ${ }^{272}$ Continued progress in recycling efforts, in addition to efforts to decrease overall household waste bound for landfills, will further the positive abatement of harmful emissions from Norway's landfills.

264. Id.

265. Id.

266. EU, Norway Join Forces on CO2 Capture and Storage, EURACTIV (May 29, 2009), http://www.euractiv.com/en/climate-change/eu-norway-join-forces-co2-capture-storage/ article-182753.

267. Id.

268. See Herzog, supra note 147 , at 2.

269. Bugge, supra note 28 , at xviii.

270. Id.

271. Id.

272. Id. 
While increased energy efficiency and alternative energy sources have been encouraged within the country, Norway's total energy consumption has increased substantially in the period between 1989 and $2001 .^{273}$ Notably, the number of vehicles on the road increased by more than one-third during that time, perhaps directly related to the fact that during the same period Norway's funding for public transportation was slashed in half. ${ }^{274}$ While the vehicles on the road in Norway are more fuel efficient than ever, once again the benefits of this positive initiative are outweighed by the overwhelming trend of "more"-more people, more trash, more cars, more consumption, and more greenhouse gas emissions. ${ }^{275}$

The lofty goals Norway set for itself in 1987 regarding climate change strategy were partially derailed by the nation's growing unemployment rates and economic downturn in the $1990 \mathrm{~s} .{ }^{276}$ The nation began to focus its attention on possible membership within the EU and the issues surrounding the EEA agreement. ${ }^{277}$ Attention turned from creating a sustainable economy centered on clean fuel processes to merely minimizing negative environmental effects within the current economic structure. ${ }^{278}$ Norway's goal of creating "an economy for the Earth-an economy for the common good"279 seems to have taken a back seat in the wake of economic downturn, perhaps due to the fact that Norway's primary source of income is related to the sale of fossil fuels. ${ }^{280}$

Because imports of fossil fuels are expected to grow to encompass eighty-five percent of the overall energy requirements in Europe as well as the United States by the year 2030, it is understandable that Norway would continue to rely upon its vast natural resources to provide economic viability for the country. ${ }^{281}$ Currently, Norway provides nearly fifteen percent of fossil fuels imported into the EU. ${ }^{282}$ Therefore, Norway is likely to continue its current oil and gas production and eventually to expand to new fields, perhaps in cooperation with Russia in the far north regions and the Barents Sea. ${ }^{283}$ The current political climate suggests that the importance of creating wealth for the nation through the sale of oil and gas

\footnotetext{
273. Id.

274. Id.

275. Id.

276. Id. at xix.

277. Id.

278. Id.

279. Id.

280. Id.

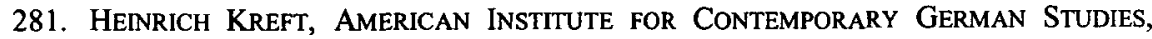
GEOPOLITICS OF ENERGY: A GERMAN AND EUROPEAN VIEW 2, available at http://www.aicgs.org/documents/kreftenergy.pdf (last visited Apr. 14, 2011).

282. Id.

283. Id.
} 
outweighs the importance of developing a sustainable alternative energy plan for the future. ${ }^{284}$

\section{Norway's Next Steps}

Norway faces difficult choices as to the next steps in the fight against climate change, with struggles emerging between the current economic conditions of citizens such as laborers in the oil and gas industry or commercial fishermen and the need aggressively to pursue other, sustainable energy sources for the future benefit of the country and the climate. $^{285}$ If Norway does not pursue changes, a degradation of its land, natural resources, and climate will certainly occur, especially given the natural increase in population and corresponding increase in gross national product expected over the next thirty years. ${ }^{286}$ However, Norway has a history of making difficult choices that are in the country's best interest, and the nation is proud to have been one of the first to implement serious agendas in order to counteract the harmful effects of carbon emissions. ${ }^{287}$ Norway needs once again to focus on the issue and move forward on a cohesive plan to create cooperation between political policy and scientific and technological possibilities regarding development of sustainable, clean energy. ${ }^{288}$ International cooperation with the current and future agendas of the EU will be vital in successfully moving both Norway and the world closer to the goal of minimizing carbon emissions and creating long term, sustainable alternatives for fossil fuels. ${ }^{289}$

While the production of fossil fuels certainly provides economic stimulus to Norway, given that it currently ranks as the world's third largest exporter of oil and natural gas, it is time to consider not only the benefits of fossil fuels but also the previously underestimated costs. ${ }^{290}$ A country that is heavily reliant upon the production of fossil fuels to sustain its economy is at the mercy of the continued "acceptability" of consumption of fossil fuels by the rest of the world. ${ }^{291}$ This "acceptability" is determined not only by the cost of acquiring the fuel, but also by the long term cost to the planet due to climate change. ${ }^{292}$ If and when the world as a whole begins to take the effects of global warming seriously, the demand for fossil fuels will

284. Bugge, supra note 28 , at xix.

285. Id.

286. Id. at $\mathrm{xix}-\mathrm{xx}$.

287. Id. at $\mathrm{xx}$.

288. Id.

289. Id.

290. Geir Westgaard, The Extended Concept of Energy Security, in EMERGING FROM THE

FROST: SECURITY IN THE 21ST CENTURY ARCTIC 74 (Kjetil Skogrand ed., 2008).

291. Id.

292. Id. 
begin to wane as countries seek clean energy alternatives. ${ }^{293}$ Any nation, including Norway, whose national economy is linked to production of fossil fuels should begin to prepare for an eventuality that could include weaker demand for oil and gas. ${ }^{294}$

Norway plays a pivotal role in combating climate change not only because it has taken a leading role in enacting policies and practices to combat greenhouse gas emissions, but also because of its unique position in the world as a major exporter of both oil and natural gas. ${ }^{295}$ Oil currently "accounts for a quarter of Norway's gross domestic product, half of [the] total exports, a third of total government income and a quarter of total investments." ${ }^{296}$ Furthermore, natural gas is expected to surpass oil as Norway's leading energy export in the near future. ${ }^{297}$ While Norway produces tremendous amounts of fuel in the form of oil and gas, the country itself relies primarily on hydropower domestically, leaving even greater amounts of oil and natural gas for export and economic benefit to the country. ${ }^{298}$ Additionally, Norway is investigating other renewable energy sources for domestic use, especially in the area of wind power. ${ }^{299}$

Norway's efforts to be the world's "most responsible citizen" regarding carbon emissions also extend to the areas of forestry and shipping. ${ }^{300}$ Unfortunately, carbon emissions also occur from both natural degradation of forests and intentional deforestation in developing countries. Harmful emissions from these sources alone total nearly seventeen percent of total greenhouse gas emissions annually. ${ }^{301}$ Norway is playing an integral part in a program known as REDD, or Reductions in Emissions from Deforestation and forest Degradation. ${ }^{302}$ In 2007 Norway pledged the equivalent of $\$ 500$ million to this program to "promote sustainable forest management, contribute to the protection of biodiversity and secure the rights, involvement and livelihood of local communities and indigenous peoples. Besides reduced greenhouse gas emissions, REDD should also promote sustainable development and poverty reduction." ${ }^{\text {"303 }}$

In a 2007 report to Parliament, Norwegian officials outlined an updated climate policy with emphasis not only on renewed efforts to reduce domestic emissions, but also on facilitating a cohesive international climate

293. Id.

294. Id.

295. Walther, supra note 123.

296. Id.

297. Id.

298. Id.

299. Id.

300. Id.

301. Id.

302. Id.

303. Id. 
agreement by working with developing countries to reduce carbon emissions. ${ }^{304}$ Regarding additional emissions reductions within Norway, the proposed plan calls for a realistic reduction of an additional thirteen million to sixteen million tons of $\mathrm{CO}_{2}$ by the year $2020{ }^{305}$ It is understood that this level of emissions reduction is unlikely to be achieved solely by existing measures, such as the carbon tax. ${ }^{306}$ Additional measures proposed to meet the emissions reduction goals include banning oil burners in new buildings, providing subsidies to convert old oil burners to alternative heat sources, developing sea windmill technology, increasing bio-energy development, improving public transportation, and creating a quota system for industries not currently covered by taxation or emissions trading. ${ }^{307}$

The measures pursued by Norway to reduce domestic greenhouse gas emissions are aggressive and not easily attained. ${ }^{308}$ However, Norway contributes only two percent to overall global emissions; therefore, even drastic domestic reductions make a relatively small impact on overall world climate improvement. ${ }^{309}$ Unfortunately, no matter how many improvements and sacrifices Norway makes, the true global polluters of the world greatly overshadow the benefits created by Norway's strides in emissions reduction. ${ }^{310}$ However, Norway is committed to being a shining example in the world, partly due to the fact that it has become one of the richest nations through the export of oil and natural gas. ${ }^{311}$

\section{PROPOSED GLOBAL IMPLEMENTATION AND INTERNATIONAL COOPERATION}

\section{A. Implementation and Adoption of Carbon Capture and Sequestration}

Norway is just one small nation on the planet, and even with a successful carbon management strategy, the effect on the global environment will be minimal. ${ }^{312}$ In order for progress to be made against climate change, countries around the world must study the lessons provided by both Norway and the European Union to determine what strategies to implement efficiently in the fight against global warming. One strategy,

304. The Norwegian Confederation of Trade Unions (LO), Climate Strategy 5 , available at http://www.lo.no/Documents/english/climate_strategy.pdf (last visited Apr. 14, 2011).

305. Id.

306. Id.

307. Id. at 5-6.

308. Id. at 6 .

309. Id.

310. Id.

311. Id.

312. AUNE \& ROSENDAHL, supra note 243 , at 248. 
recognized as crucial by the EU ETS, ${ }^{313}$ is CCS technology. ${ }^{314}$ Carbon capture and storage will allow the world to continue to use fossil fuels for the foreseeable future, while at the same time mitigating the harmful effects on the environment. ${ }^{315}$ With the ability to use fossil fuels more responsibly, the world will have time to gradually develop an infrastructure that can be run on clean, alternative fuel sources. ${ }^{316}$

Norway's experimentation and perfection of CCS technology should be recognized and mimicked by countries throughout the world in order to combat global emissions. Because the world remains highly dependent upon fossil fuels and, until viable alternative fuels can be effectively integrated, ${ }^{317} \mathrm{CCS}$ technology can play a vital role in combating carbon emissions. ${ }^{318}$ The oil and gas exported from Norway is possibly the "cleanest" fuel source in terms of carbon emissions, due to the extraordinary efforts of Norway to utilize CCS to minimize greenhouse gas emissions during the extraction and production of fuel. ${ }^{319}$ Countries around the world need to follow Norway's example and incorporate this technology in order to create additional "clean" fuel sources.

\section{B. Adoption of a Subsidy-Free Taxation Scheme}

A key variable that participating countries must address is the choice of emission allowances or taxation. If taxation is used, participating countries must determine how to apply the tax structure. Currently, Norway's carbon emission strategy primarily taxes industries that can afford taxation and subsidizes or excludes industries that cannot afford taxation. ${ }^{320}$ Many economists who believe that all greenhouse gas emissions should be taxed equally without any form of subsidy frown upon such a taxation scheme..$^{321}$ A subsidy-free taxation scheme is further preferred as various studies assert that, although Norway's taxes led to a substantial increase in the price of several types of fuel, the attributable decrease in carbon emissions equated to only $2.3 \%$ over the ten year time period from 1990 to $1999 .{ }^{322}$ The assertion is that "[t]his surprisingly small effect relates to the extensive tax exemptions and relatively inelastic

313. "On March 26, 2009, the European Parliament and Council approved a Directive that expressly recognizes carbon capture and storage (CCS) as a "bridging technology that will contribute to mitigating climate change."' COLE, supra note 6 (manuscript at 41).

314. See discussion supra Part II.B.

315. See discussion supra Part II.B.

316. See discussion supra Part II.B.

317. See Greenhouse Gas Emissions, supra note 7.

318. See discussion supra Part II.B.

319. AUNE \& ROSENDAHL, supra note 243, at 251.

320. See id.

321. Id.

322. BRUVOLL \& LARSEN, supra note 29 , at 1. 
demand in the sectors in which the tax is actually implemented. The tax does not work on the levied sources, and is exempted in sectors where it could have worked.",323

Norway is unique in that the majority of its energy is derived from clean electricity produced from hydropower. ${ }^{324}$ Given the fact that emission-free electricity is a readily available power source, Norway's high carbon taxes have served to move industries away from fossil fuel energy sources and toward substituting electricity as an energy source whenever possible. ${ }^{325}$ This has occurred because the cost to re-tool for electricity is often lower in the long run than paying the high carbon taxes for the continued use of oil or natural gas. ${ }^{326}$ Unfortunately, many of the industries that create the highest emissions from fossil fuel use are the same industries that are exempted from the carbon taxes, thereby drastically reducing the positive environmental effects of the tax, as these industries have no economic incentive to re-tool from fossil fuel energy sources to clean electricity. ${ }^{327}$ Overall, studies have determined that

Norwegian carbon taxes are high, but the emissions effect is low. This implies a high cost of reducing emissions from sources on which the tax is levied. For countries that consider implementing a carbon tax and in future Norwegian carbon tax policy, . . . a more broad based, cost efficient tax, which is uniform for all sources and greenhouse gases [is recommended]. With a more uniform distribution of the tax burden, it is possible to accomplish larger reductions in the greenhouse gas emissions at lower costs. ${ }^{328}$

For countries looking to implement carbon taxes as part of an emissions reduction strategy, Norway's taxation system should be carefully analyzed as to its structure and measureable results. ${ }^{329}$ Norway's carbon tax scheme is more influenced by politics than by pure economics; therefore, the results of Norway's carbon tax scheme are compromised. ${ }^{330}$ After studying the multitude of exemptions contained within Norway's carbon taxes, ${ }^{331}$ a subsidy-free plan that taxes all emissions from all sources equally is likely to provide the most effective environmental benefits. ${ }^{332}$ A subsidyfree plan would encourage the minimization of fossil fuel use where possible and the investment into clean, alternative fuel sources where

323. Id.

324. Id. at 8.

325. Id. at 16 .

326. Id.

327. Id. at 22 .

328. Id. at 23 .

329. See discussion supra Parts II, IV.A, IV.C.

330. See discussion supra Part IV.A.

331. See discussion supra Part IV.A.

332. See AUNE \& ROSENDAHL, supra note 243 , at 250. 
economically feasible. ${ }^{333}$ When all sources and industries are taxed equally, the greatest reduction in emissions will likely be realized.

\section{Necessary Global Cooperation and Implementation}

The goal of minimizing global carbon emissions and creating long term, sustainable alternatives for fossil fuels is only possible through international cooperation. Such cooperation and implementation has proven difficult for many countries, including the United States. While the United States recognizes the importance of reducing carbon emissions, it has been impossible to enact legislation on a national level. ${ }^{334}$ To date, national legislative proposals regarding climate change have failed, and only a nonbinding resolution has passed. ${ }^{335}$ On May 23, 2006, the U.S. Senate Foreign Relations Committee passed Senate Resolution 312, a nonbinding resolution on climate change. ${ }^{336}$ The Sense of the Senate Resolution on Climate Change ${ }^{337}$

acknowledges the growing scientific consensus that human activity is causing an accumulation of greenhouse gases in the atmosphere. It also asserts that Congress should enact a mandatory national program that slows, stops and reverses the growth of greenhouse gas emissions using a marketbased structure. It notes that such a program would not be likely to significantly harm the U.S. economy and should encourage major U.S. trading partners to adopt similar programs. ${ }^{338}$

The nonbinding resolution, which acknowledges both the problem of greenhouse gas emissions and the need for the United States to implement a national program to counter the problem, stops well short of providing any possible solutions. ${ }^{339}$ The United States is a major contributor to the global problem of climate change, and it is time for the United States seriously to

333. See BRUVOLL \& LARSEN, supra note 29 , at 1.

334. See id. at 46.

335. Congressional Proposals regarding climate change including the Climate Stewardship Act of 2003, the Clean Air Planning Act of 2003, the Clean Power Act of 2003, the Clean Smokestacks Act of 2003, the Climate Stewardship and Innovation Act of 2005, and the Climate and Economy Insurance Act of 2005 have all failed to date. Id.

336. The Lugar-Biden Climate Change Resolution, S. Res. 312, 109th Cong. (2006).

337. See Williams et AL., supra note 5, at 43. See also Energy Policy Act of 2005, H.R. 6, 109th Cong. (2005) and Energy Policy Act of 2005, H.R. 6, 109th Cong. (2005) (S.Amdt.866) (detailing the Energy Policy Act of 2005 and the amendment by Senator Bingaman).

338. WILliamS ET AL., supra note 5, at 43.

339. See id. 
consider the examples provided by Norway and the EU and create a viable plan to reduce carbon emissions.

Although national legislation within the United States has failed at every turn, there has been successful legislation put in place at the state level. The California Global Warming Solutions Act of $2006^{340}$ was signed into law on August 31, 2006, making California the first state to place a mandatory limit on greenhouse gas emissions. ${ }^{341}$ The law calls for a onequarter reduction in emissions by the year 2020 through the use of a capand-trade system that will cover all electricity utilized within the state. ${ }^{342}$ The success of this legislation could lead to further legislation in other states and on a national level; however, failure to achieve the goals or implement the legislation in an economically feasible manner could spell doom for future legislation at the national level. ${ }^{343}$

Given the complex bureaucracy and current political chasm within the United States, it may prove difficult to enact sweeping federal regulations for either carbon taxes or cap-and-trade policies. ${ }^{344}$ Instead, a more feasible recommendation may be to continue the agenda at the state or regional level where policies are enacted that will work effectively within that state or region. ${ }^{345}$ Then, once mechanisms are in place regionally, cooperation across state lines or within regions can be integrated and the agenda to reduce carbon emissions can be expanded. ${ }^{346}$ This is akin to considering Norway as a "state" which implemented its own agenda to reduce harmful emissions, and that "state" is now working in cooperation with the EU to expand and improve its agenda. ${ }^{347}$ Additionally, the United States and other concerned countries need to study the feasibility of applying the CCS technology implemented in Norway in order to continue the use of fossil fuels while simultaneously reducing emissions. ${ }^{348}$ The technology is available and successful, and the cost to implement it should be considered an extremely important and beneficial investment for both industries and state and national governments. ${ }^{349}$ The United States should look to Norway and the EU as an existing paradigm rather than attempting to reinvent the emissions reduction wheel. ${ }^{350}$

340. CAL. Gov'T. CODE $§ 12890$ (West 2010).

341. See Samantha Young, Schwarzenegger Signs Global Warming Bill, WaSHINGTON Post, Sept. 27, 2006, http://www.washingtonpost.com/wp-dyn/content/article/2006/09/27/ AR2006092700174_pf.html.

342. Id.

343. WILlIAMS ET AL., supra note 5, at 45.

344. See id. at 30.

345. Id. at 46.

346. Id.

347. Id.

348. Id.

349. Id.

350. Id. 


\section{CONCLUSION}

Two decades ago, the small country of Norway made an important decision to enact policies aimed at reducing the amount of carbon emissions created within its borders. ${ }^{351}$ Aggressive carbon taxes were enacted affecting many industries, and several positive results occurred. ${ }^{352}$ First, a concerted effort was made to switch to alternative, cleaner sources of energy whenever the substitution was economically feasible. ${ }^{353}$ Second, a portion of the taxes collected was set aside and invested by the government to provide for the future stability of Norway. ${ }^{354}$ This investment fund has become the third largest sovereign fund in the world and is aimed at providing revenue for future Norwegian generations in the event that revenue can no longer be created by the production and export of fossil fuels. ${ }^{355}$ Third, and perhaps most importantly, CCS technology was developed as a primary method of avoiding excessive carbon taxation. ${ }^{356}$ This technology may prove to be beneficial to both the economy and the environment of not only Norway, but also of concerned nations around the world. 357

While Norway has taken great strides in the fight against greenhouse gas emissions, the rest of the world has taken action as well. ${ }^{358}$ The European Union has taken a leading role and has created a large, verifiable marketplace to trade emissions allowances across the EU and incoming Member States. ${ }^{359}$ The EU ETS has been painstakingly developed and refined and is currently mandated for all Member States. ${ }^{360}$ The EU ETS strategy to reduce emissions in the EU is working within the Member States and is producing cooperation in many areas with non-Member States, including Norway. ${ }^{361}$

After two decades of aggressively pursuing a strict emissions reduction strategy, the results of Norway's efforts remain mixed. ${ }^{362}$ Several positive benefits have occurred, but the actual emissions reductions are less than hoped for, given the aggressive policies. ${ }^{363}$ Once the EU began actively pursuing an emissions reduction strategy that was based on a

351. See discussion supra Part II.

352. See supra notes 129-141 and accompanying text; discussion supra Part II.A.

353. See supra notes 131-134 and accompanying text.

354. See supra notes $135-141$ and accompanying text.

355. See supra notes $135-141$ and accompanying text.

356. See discussion supra Part II.B.

357. See discussion supra Part II.B.

358. See discussion supra Part III.

359. See discussion supra Part III.B.

360. See EU Emissions Trading System (EU ETS), supra note 189.

361. See discussion supra Part III.E.

362. See discussion supra Part IV.

363. See discussion supra Part IV.A. 
system of allocation rather than a direct tax, questions emerged as to whether Norway would abandon its current path. ${ }^{364}$ However, the result has been that the EU's efforts have spurred Norway to forge ahead, combining its own strategies with many of those included in the EU plan. ${ }^{365}$ Norway has rededicated itself to the pursuit of meaningful change by continuing, and likely expanding, its current carbon taxation along with incorporating cooperation with the EU ETS strategies. ${ }^{366}$

Norway is a prime example of what can be accomplished by a small country that is dedicated to making a difference. Although Norway's economy is heavily reliant on energy production, Norway still took a difficult and dedicated stance to reduce the harmful environmental effects of fossil fuel production and use. ${ }^{367}$ While there have been bumps in the road, and not all of Norway's goals have been met as far as emissions reductions are concerned, many positive benefits have been realized. ${ }^{368}$ If true progress is to be made in the fight against global warming, the countries of the world must seriously evaluate and utilize the information that can be gained from Norway's two-decade long fight to reduce carbon emissions and improve the future of the planet. ${ }^{369}$

364. See discussion supra Part IV.B.

365. See discussion supra Part IV.B.

366. See discussion supra Part IV.B.

367. See discussion supra Part II.

368. See discussion supra Part IV.C.

369. See discussion supra Parts II, IV. 
